\title{
Do sentido ao valor: relações teóricas entre a Semântica de Michel Bréal e o Estruturalismo de Ferdinand de Saussure
}

\author{
From meaning to value: theoretical relationship \\ between Bréal's Semantics and Saussure's Structuralism
}

Cristiane Dall'Cortivo-Lebler

Universidade de Santa Cruz do Sul, Santa Cruz do Sul, Rio Grande do Sul / Brasil cristianedc@unisc.br

Resumo: Desde o ano de1916, com a publicação do Curso de Lingüistica geral, os rumos dos estudos acerca da linguagem humana ganharam uma nova perspectiva graças à exposição do pensamento de Ferdinand de Saussure pelos seus discípulos. Alguns anos antes, em 1897, entretanto, outra obra fundamental, mas pouco conhecida e debatida, foi lançada ao público: o Ensaio de Semântica, de Michel Bréal. O presente trabalho traça um paralelo entre alguns conceitos apresentados nas obras Curso de Linguística geral e Escritos de Lingüistica geral, atribuídas a Ferdinand de Saussure, e o Ensaio de Semântica, de Michel Bréal, a fim de verificar em que medida é possível estabelecer relações entre os teóricos. A hipótese apresentada é de que o compartilhamento de ideias entre os linguistas, em Paris, bem como o momento histórico em que ambos desenvolveram suas pesquisas foram decisivos para a formulação de suas teorias acerca da linguagem.

Palavras-chave: Ferdinand de Saussure; Michel Bréal; história das ideias linguísticas.

Abstract: The Course in General Linguistics written by Charles Bally and Albert Sechehaye was published in 1916 and, since then, studies about human language have gained a new perspective due to Ferdinand de Saussure's thoughts spread by his followers. However, some years 
earlier, in 1897, another important work, but lesser known and debated, was launched to the public: the Semantic Essay, by Michel Bréal. This paper aims to provide a parallel between some concepts presented in Course in General Linguistics and Writings of General Linguistics, works attributed to Ferdinand de Saussure, and the Semantic Essay, written by Michel Bréal, in order to verify in what extent it is possible to establish relationships between the theorists. The hypothesis is that the ideas shared between the linguists, in Paris, as well as the historical moment in which both developed their researches were decisive for the formulation of their theories about language.

Keywords: Ferdinand de Saussure; Michel Bréal; History of linguistic ideas.

Recebido em: 9 de maio de 2016. Aprovado em: 10 de outubro de 2016.

\section{1 "A ideia deste trabalho"}

É citando Michel Bréal que iniciamos este trabalho, atribuindo à nossa introdução o mesmo título dado pelo autor à introdução da obra Ensaio de Semântica (ES), publicada originalmente na França, em 1897, e traduzida para o português no ano de 1992, na qual Michel Bréal apresenta aos seus leitores uma nova ciência que, à época, denominou Semântica.

Nosso trabalho, entretanto, em nada se assemelha à importância e ao pioneirismo daquele de Bréal. Bem mais modesto, nosso objetivo é traçar um paralelo entre as ideias apresentadas no Ensaio de Semântica, de Michel Bréal, e aquelas expostas em duas obras de Ferdinand de Saussure: o Curso de Linguística Geral (CLG) e os Écrits de Linguistique Général (Écrits).

Eduardo Guimarães (1992, p. 9), no prefácio ao Ensaio de Semântica, destaca a ênfase dada pela história da Linguística ao corte, considerado por muitos como categórico, proporcionado pelo Curso de Linguística Geral. Para o autor, o conhecimento da obra de Bréal seria importante para "desautomatizar as leituras do Curso", na medida em que proporcionaria uma reflexão situada teoricamente a respeito das ideias saussurianas. No Brasil, raros são os trabalhos que têm como tema a obra 
de Bréal e mais rara ainda é a menção ao estudioso nos cursos de Letras. Seide (2012) aponta que mecanismos de busca eletrônica elencam em torno de sessenta trabalhos, publicados no Brasil, que tratam da obra de Bréal nas áreas de Linguística, Ciências da Informação, Biblioteconomia e Educação.

Para esta releitura do pensamento desses dois teóricos, nos valemos, além do estudo das referidas obras, da leitura de trabalhos desenvolvidos por comentaristas e estudiosos tanto de Saussure quanto de Bréal, especificamente no que tange às transformações das línguas, à ideia de língua como inerente ao homem e não vista como um organismo vivo, além dos conceitos de mudança linguística, de arbitrariedade e de valor. A hipótese que delineamos para esta pesquisa é de natureza histórica e teórica. Vários são os episódios que demonstram a admiração que Bréal tinha por Saussure e o convívio entre eles: a indicação de Bréal para que Saussure atuasse na École Pratique des Hautes Etudes, as correspondências entre Henri de Saussure - pai de Saussure - e Bréal, para quem escreveu a fim de comunicar a presença do filho em Paris, bem como o fato de Bréal considerar seriamente a possibilidade de Saussure sucedê-lo no Collège de France. A isso se acrescenta que ambos produziram suas mais célebres ideias no período em que houve o surgimento de um novo movimento nos estudos linguísticos, o movimento Neogramático, que tinha por objetivo dar à Linguística um caráter mais científico, distanciando-a da visão romântica que predominava na época (BOUISSAC, 2012).

Ainda como justificativa para este trabalho, soma-se o fato de considerarmos a reflexão epistemológica importante nos estudos da linguagem, especialmente porque tem por característica objetos construídos a partir de determinados pontos de vista, tal como pontua Saussure (2006), quando trata das dificuldades em definir o objeto em Linguística. Ao comentar as diferenças entre a definição do objeto em Linguística e em outras ciências, o autor afirma que "bem longe de dizer que o objeto precede o ponto de vista" - tal é o caso das ciências que trabalham com objetos definidos de antemão - "diríamos que é o ponto de vista que cria o objeto" (CLG, p. 15).

Oswald Ducrot, na apresentação da obra Logique, Structure, Énonciation (1989), ressalta a necessidade da constante reflexão sobre a tradição linguística, de modo a tornar menos automático o trabalho a respeito da linguagem ou, em último lugar, não se saberá mais de que 
se fala exatamente quando se trata de fatos e de teorias linguísticas. Ducrot (1989) ancora suas reflexões na afirmação de Pierre Duhem, para quem "os fatos de hoje são construídos com as teorias de ontem", pois, segundo Ducrot, não é possível observar os fatos de linguagem (ou o objeto para Saussure) que não seja através de uma teoria já existente (o que equivaleria ao ponto de vista criador desse objeto).

Este trabalho, certamente, não esgota o tema que se propõe a discutir, também abordado de modo periférico e com outros propósitos por Seide (2006). Entretanto, acreditamos que este pode ser um debate interessante na medida em que lança olhares ainda pouco explorados a respeito do legado saussuriano, especialmente no ano em que se comemoram cem anos de publicação do $C L G$.

A fim de alcançarmos nosso propósito, iniciamos esta exposição com uma breve biografia de Saussure, relatando o início de sua vida acadêmica em Leipzig e o contato com Bréal quando da mudança para Paris. Em seguida, abordamos, em linhas gerais, o contexto em que ambos os teóricos desenvolveram suas pesquisas, de modo a situá-las historicamente. Em seguida, escolhemos, para debate, alguns conceitos presentes nas obras de ambos os autores. Após, apresentamos as considerações finais.

\section{Bréal e Saussure: a convivência do mestre com o jovem linguista}

Ferdinand de Saussure (1857-1913) iniciou sua vida de estudante em Linguística em 1876, aos 19 anos, na cidade de Leipzig, na Alemanha. Lá, juntamente com outros linguistas, como Georg Curtius (18201885) e August Leskien (1840-1916), Saussure buscava explicações para as diferenças existentes entre as línguas europeias, apesar de sua base comum. Sua hipótese ultrapassava as comparações entre línguas realizadas na época e contrariava as ideias vigentes até então, decorrentes do darwinismo e sustentadas, especialmente, por August Schleicher, segundo as quais as línguas se comportariam como "organismos vivos" (BOUISSAC, 2012). Dessa pesquisa, resultou o trabalho monográfico denominado Mémoire sur le système primitif des voyelles dans les langues indo-européenes, publicado em Leipzig, em 1878, quando Saussure tinha 21 anos.

Após esse aclamado trabalho, o jovem linguista mudou-se para Berlin, onde viveu por dois anos, a fim de estudar céltico e sânscrito. 
Passado esse período, Saussure retornou a Leipzig, onde encerrou sua vida de estudante e sua passagem pela Alemanha com a defesa da tese de doutorado, na Universidade de Leipzig, sobre o genitivo absoluto em sânscrito, publicada em francês no ano de 1880. Nesse momento, o jovem linguista tinha apenas vinte e três anos e, desde os dezessete, participava da Société Linguistique de Paris, onde seus trabalhos eram muito bem recebidos. Em meados de 1880, Saussure mudou-se para Paris e passou a residir no Quartier Latin, bairro em que se situam as principais universidades francesas, como a Université Sorbonne e o Collège de France.

Lá, teve aulas com importantes pesquisadores da época, como Louis Havet, que havia resenhado sua Mémoire, em 1878, e com Michel Bréal (1832-1915), por quem era notadamente admirado (BOUISSAC, 2012). Saussure já havia demonstrado seu particular talento como linguista em suas publicações - especialmente na Mémoire - e nas aulas de Havet, que frequentara no Collège de France. Essas habilidades foram imediatamente notadas por Bréal, que, no ano seguinte, o indicou para substituí-lo como Maître de Conférence de gothique et de vieux-haut allemand na École Pratique des Hautes Études.

Ali, durante dez anos, Saussure lecionou cursos variados, desde Fonética, passando pelas gramáticas gótica, comparada do grego e do latim, e línguas como o alto-alemão antigo, o escandinavo antigo e o lituano (ARRIVÉ, 2010; GODEL, 1969). Nesse período, Saussure teve mais de cem alunos, um número considerado elevado para o tipo de aulas ministradas e para a época. Além das atividades de pesquisador e professor, Saussure exerceu também atividades administrativas, sendo Secretário Geral da Société Linguistique de Paris, posto também ocupado por Bréal em 1868.

Finalmente, em 1891, Saussure decide retornar a Genebra sem que ninguém soubesse exatamente o motivo. Arrivé (2010) apresenta a hipótese de Saussure ter se recusado a adotar a nacionalidade francesa, algo imprescindível para assumir o posto de Bréal no Collège de France. Entretanto, à época, Bréal tinha apenas cinquenta e nove anos e sua aposentadoria só aconteceria quinze anos depois, em 1906, quando completaria setenta e quatro anos.

Estudiosos de Saussure e Bréal não apontam indícios que justifiquem que a convivência entre ambos tenha sido decisiva para a aproximação teórica. Além disso, poucos são os trabalhos que tangenciam 
essa possível relação entre as ideias dos dois linguistas. Entretanto, consideramos importante o fato de ambos os estudiosos terem mantido contato, o que permitiu que Saussure conhecesse o trabalho do semanticista e que este, por sua vez, acompanhasse o desenvolvimento das ideias do jovem genebrino. Ademais, como afirmamos anteriormente, o momento histórico do andamento dos trabalhos dos teóricos proporcionou que suas ideias se tornassem um marco nos estudos da linguagem: a fundação da disciplina semântica além de mudanças consideráveis nas transformações da Ciência Linguística.

Aarsleff (1981) aponta que o papel de Bréal na história da Linguística sempre foi ocultado e até mesmo relegado à sombra, e que sua principal obra, o Ensaio de Semântica, raramente é lida. Essa afirmação se verifica na escassez de trabalhos que tomam como tema a Semântica de Bréal ou que simplesmente o mencionem como importante figura no desenvolvimento dos estudos da linguagem. Seu nome eventualmente figura em disciplinas que tratam da Semântica e da Pragmática, muitas vezes com o mero objetivo de identificá-lo como aquele que cunhou o termo semântica, tal como nos lembra Guimarães (1992). Aarsleff(1981, p. 26), entretanto, pondera que os seminários ministrados por Saussure na École des Hautes Études impuseram uma marca decisiva à linguística francesa, especialmente por reforçar as ideias de Bréal e por preparar a recepção daquelas de Meillet, para quem Michel Bréal e Ferdinand de Saussure foram responsáveis por dar à escola francesa de linguística comparada uma característica própria.

\section{Contexto histórico}

Ferdinand de Saussure foi contemporâneo de Michel Bréal e ambos viveram um momento de renovação no modo como a linguagem era estudada: o surgimento dos Neogramáticos, que se caracterizaram como uma reação ao modo, vigente na época, de conceber e de estudar as línguas, denominado, ainda, de Gramática Comparativa.

Câmara Jr. (1969) enfatiza que, no período das gramáticas comparadas, as línguas eram vistas como sujeitas a um processo histórico de evolução. Esse ponto de vista em relação às línguas tem como base duas explicações: a hipótese da existência de uma língua primitiva e os ideais darwinistas. A primeira das explicações é a ideia da existência de uma protolíngua, o proto-indo-europeu, ou seja, uma língua primeira 
em relação a todas as outras, da qual se teriam originado várias famílias (ou blocos) linguísticas(os) - como as línguas gregas, latinas, persas, germânicas e o sânscrito. O método criado para dar sustentação a essa perspectiva baseava-se na comparação das formas linguísticas através do cotejo de palavras inteiras, de partes de vocábulos, de consoantes ou de vogais. As línguas comparadas poderiam ser línguas geograficamente distantes ou contíguas, tal como as línguas indígenas das Américas do Sul, Central e do Norte (CÂMARA JR., 1969).

Além disso, o segundo fator motivador para o desenvolvimento desse ponto de vista é o surgimento das ideias de Darwin sobre a evolução das espécies. Dois dos maiores expoentes dessa época são os linguistas alemães Franz Bopp (1791-1867) e August Schleicher (1821-1868), cujos interesses centraram-se no estudo do sânscrito, antiga língua da Índia. Schleicher, assim como muitos linguistas de sua época, tinha o desejo de transformar os estudos da linguagem em uma verdadeira ciência, sustentada por leis que orientassem e que explicassem as mudanças nas línguas, tal como postulado pelas ciências naturais.

Segundo afirma Câmara Jr. (1975), Schleicher, que também era botânico, reclamava aos estudos da linguagem seu lugar entre as ciências da natureza, em oposição à filologia, por considerar que as línguas não seriam um ramo da história, mas das ciências naturais, visto que seu desenvolvimento se assemelharia ao de um ser vivo. Leis determinavam desde o seu nascimento até a sua morte: as línguas nasciam, evoluíam, definhavam e, por fim, eram extintas, tal como ocorre, na natureza, com as espécies. Schleicher postulava que, para cada grupo ou subgrupo de línguas, havia uma língua mãe e línguas filhas, todas elas organizadas em árvores genealógicas.

As ideias de Schleicher foram imediatamente contestadas por linguistas que o sucederam, dentre os quais Bréal e Saussure. Além disso, a classificação arbórea das línguas proposta pelo linguista alemão é considerada hoje de excessiva simplificação a respeito do desenvolvimento do indo-europeu. Um dos argumentos apresentados em favor dessa tese é de que a semelhança entre as línguas não poderia ser comprovada a partir de uma única origem. Linguistas cujos trabalhos foram desenvolvidos em períodos posteriores à publicação das ideias de Schleicher negam até mesmo a existência de um proto-indo-europeu (CÂMARA JR., 1975). Outro argumento apresentado é de que a aparente semelhança entre as línguas, tanto no léxico - em maior grau - quanto 
na gramática - em menor grau -, poderia ser fruto de empréstimos linguísticos e de contatos entre línguas (LYONS, 1979).

Câmara Jr. (1975) admite que a publicação da obra $A$ origem das espécies (1859), por Charles Darwin, pode ter influenciado as ideias de Schleicher, embora se afirme que tal influência possa ser superficial, já que a publicação de $A$ Teoria de Darwin e a Linguagem (1863), de Schleicher, teria tido muito mais influência da filosofia hegeliana, cujos contornos seriam meramente preenchidos pelas ideias darwinistas (PICKERING, 2011).

É nesse contexto, em que o estudo da linguagem era essencialmente diacrônico, que Saussure e Bréal desenvolveram suas hipóteses sobre a explicação do funcionamento da linguagem: aquele abordando desde aspectos gerais até elementos específicos da linguagem, como a fonologia; e este se centrando no estudo do modo como o sentido é atribuído às palavras da língua e como este se transforma ao longo do tempo, incluindo questões bastante gerais a respeito do funcionamento da linguagem, tal como veremos nas próximas páginas.

\section{Aproximações teóricas entre Bréal e Saussure}

Para Aarsleff (1981), Bréal desenvolveu, tanto no Ensaio de Semântica quanto em trabalhos anteriores a ele, considerações gerais sobre a linguagem, ultrapassando uma mera ciência do significado-modo como muitos, até os dias atuais, conhecem o trabalho de Bréal -, chegando até mesmo a estabelecer uma teoria que explicasse o funcionamento da linguagem - esta vista como inerente ao homem: "tudo, na linguagem, vem do homem e se endereça ao homem" (ES, p. 195).

Os princípios dessa "linguística geral" brealiana ressurgiriam mais tarde, no Curso de Linguística Geral. Alguns deles aparecem segundo uma mesma terminologia - língua, fala, valor - enquanto outros não chegaram a ser cunhados terminologicamente por Bréal, mas se assemelhariam às definições de sincronia, de diacronia, de sintagma, de estrutura, dentre outros aspectos, como o arbitrário do signo e a língua como algo socialmente dado e como fruto da coletividade.

Aarsleff (1981) credita o desapreço de Bréal pela terminologia especialmente a dois motivos: primeiramente, ao fato de ser um acadêmico que, avesso às formalidades da academia, considerava plausível escrever sobre diversos temas para um público mais amplo 
que aquele interessado estritamente em temas relativos às ciências da linguagem, o que pressupunha uma escrita mais clara e livre de vícios. Além disso, eram frequentes, em seus ensaios, críticas a trabalhos publicados em sua época, especialmente pela falta de clareza e de método que os perpassava.

Apesar de combater fortemente os postulados dos comparatistas, não é possível afirmar que Bréal não tenha sofrido qualquer influência dessa escola, especialmente no que diz respeito à identificação de leis que governariam as transformações pelas quais passam as línguas. Isso se torna evidente na obra do autor pela definição de leis responsáveis pela semântica das línguas, especialmente na primeira parte da obra, As leis intelectuais da linguagem, publicada, inicialmente, em 1883. Entretanto, sua crítica aos estudos da Gramática Comparada é bastante contundente. Ela aparece logo na apresentação da obra Ensaio de Semântica:

Os livros de gramática comparada se sucedem, no uso dos estudantes e do grande público, entretanto, não me parece que o que se oferece seja bem o que seria preciso. [...] Há, parece-me, outra coisa a fazer: extrair da linguística o que dela ressalta como alimento para a reflexão e - não temo a acrescentar - como regra para a nossa própria linguagem, visto que cada um de nós colabora com sua parte para a evolução da fala humana. (ES, p. 17).

Para Bréal, muito mais do que ter por objeto comparações entre línguas com o objetivo de evidenciar as mudanças pelas quais passaram, a Linguística deveria tomar a linguagem como o "lugar" onde "a humanidade deposita as aquisições de sua vida material e moral" (ES, p. 17), o que significa caracterizá-la como algo construído socialmente, como fruto da coletividade.

A recusa à perspectiva sobre a linguagem desenvolvida pelos comparatistas, entretanto, não se restringe à obra de Bréal. Saussure também foi crítico do trabalho desses estudiosos. Robert Godel (1969) apresenta como epígrafe da obra Les sources manuscrites du Cours de Linguistique Générale de Ferdinand de Saussure uma passagem do primeiro curso ministrado por Saussure, em 1907, cuja fonte são os manuscritos de Riedlinger. Lê-se na referida passagem: 
O gramático pode considerar a palavra de outro ponto de vista que não seja somente aquele da separação material dos elementos (é verdade que essa dissecação, atualmente, se tornou principal em linguística!) (GODEL, 1969, p. 07) (tradução nossa) ${ }^{1}$

Ambos os linguistas compartilhavam, portanto do posicionamento de que os estudos acerca da linguagem deveriam ir além da simples comparação entre línguas e da identificação de parentesco entre elas. À Linguística caberia uma tarefa muito maior: a de colocar os estudos da linguagem dentre as ciências humanas, tendo em vista não apenas a história das línguas, mas a presença das línguas na sociedade e o papel do homem nas suas transformações, como veremos nas páginas a seguir.

\subsection{A Linguística como uma ciência histórica}

A questão da Linguística como uma ciência histórica é debatida por Bréal especialmente no capítulo do Ensaio de Semântica, denominado A Linguística é uma ciência Natural?, no qual o autor apresenta argumentos contrários à perspectiva vigente à época. O primeiro deles, que se destina a classificar a Linguística como uma ciência histórica, é decisivo, já que a linguagem, para ele, não tem existência individual na natureza, mas somente na natureza humana: "a linguagem é um ato do homem: ela não tem realidade fora da atividade humana"; "fora do nosso espírito, a linguagem não tem vida nem realidade" (ES, p. 195; p. 181).

Para Bréal, se se toma o termo natureza em um sentido mais abrangente, nele caberão certamente o homem e tudo aquilo que resulta de sua ação. Entretanto, ao admitir que há diferenças entre a ciência histórica e a ciência natural e que o homem é peça-chave na história do universo, "a linguagem, que é obra do homem, não poderá ficar do outro lado [do lado das ciências naturais], e a linguística, como consequência necessária, fará parte das ciências históricas.” (ES, p. 168).

Além de situar a Linguística, de um modo geral, no terreno das ciências da história, o autor também coloca nesse campo o estudo do significado, já que, para ele, todas as mudanças que ocorrem nas línguas,

\footnotetext{
${ }^{1}$ Le grammairien peut considérer le mot d'un autre point de vue que celui de la matérielle séparation des éléments (il est vrai que cette dissection est maintenant devenue principale en linguistique!) (GODEL, 1969, p. 7)
} 
não só de natureza gramatical ou sintática, mas, também, de natureza semântica, se devem à ação do homem e não são nada mais que um pequeno acontecimento histórico.

Essa tomada de decisão em relação à natureza da ciência que desenvolve influenciou inexoravelmente a essência da obra de Bréal. É a condição de "ponto de vista" de que fala Saussure, como definidor do objeto. Trata-se de ver o objeto a partir de certa perspectiva, sendo esta, também, determinada pela natureza do objeto: é pelo fato de a linguagem estar na essência do homem que é impossível classificá-la como um quarto reino da natureza.

Tal posicionamento a respeito do lugar dos estudos da linguagem dentre as ciências vigentes à época também é apresentado por Saussure, seja em anotações de seus ex-alunos - tornadas públicas por Godel (1969) na obra Sources manuscrites du Cours de Linguistique Générale de Ferdinand de Saussure ou por Bally e Sechehaye no Curso de Linguística Geral (1916/2006) -, seja pelas próprias palavras de Saussure, conhecidas através dos seus Escritos (2002).

Saussure (2006, p. 9-10), apesar de afirmar que os trabalhos dos comparatistas têm seu mérito pelo fato de terem aberto um novo e profícuo campo de estudos, não os reconhece como uma verdadeira ciência, por faltar-lhes dois caracteres considerados por ele essenciais: a definição da natureza do seu objeto de estudo e, consequentemente, a incapacidade de determinar um método claro. Além disso, o autor sustenta que a comparação entre as línguas é inconclusiva: seus resultados não mostram nada além da história das línguas - inclusive limitadas às indo-europeias - sem caracterizar o que significavam exatamente as semelhanças descobertas. Faltava aos comparatistas uma visão mais ampla relativa à linguagem enquanto faculdade que tem sua existência no homem.

$\mathrm{Na}$ primeira conferência na Universidade de Genebra, ao questionar se os estudos acerca da linguagem teriam seu lugar na Faculdade de Letras ou na Faculdade de Ciências, Saussure afirma que considerar os estudos da linguagem como uma ciência natural é mergulhar em uma profunda ilusão, cujo debate, para ele, já está encerrado. Quanto mais se penetra na verdadeira natureza dos fatos da linguagem, mais se 
torna evidente que "a ciência da linguagem é uma ciência histórica e nada mais que uma ciência histórica" (Écrits, p. 148) (tradução nossa). ${ }^{2}$

Para Saussure (2002), uma maneira um pouco superficial de compreender como a linguística é uma ciência histórica é considerar que não se conhece completamente um povo, uma nação, se não se conhece - ou se não se tem uma ideia - do que é a sua língua. Além disso, a língua é um legado que caracteriza uma época e uma sociedade, já que está impregnada na vida social, política e literária dos povos - portanto, ligada ao homem enquanto um ser social, político e capaz de produzir cultura a partir da linguagem articulada. Na mesma conferência citada, o autor contraria a ideia de organicidade natural das línguas e a ação de leis gerais como operadoras da mudança linguística:

Quanto mais estudamos uma língua, mais penetramos no fato de que tudo na língua é história, ou seja, que ela é um objeto de análise histórica e não de análise abstrata, que ela se compõe de fatos e não de leis, que tudo o que parece orgânico na linguagem é, em realidade, contingente e completamente acidental. (Écrits, p. 149) (grifos do autor, tradução nossa). ${ }^{3}$

Godel (1969) acrescenta a essa passagem as palavras abaixo:

Para que uma ciência seja uma ciência histórica, é necessário que seu objeto represente atos do homem, regidos pela vontade e pela inteligência, e que interesse à coletividade. (GODEL, 1969, p. 38) (tradução nossa). ${ }^{4}$

A questão de que o desenvolvimento da linguagem é um empreendimento humano, a partir da ação de muitas vontades e da inteligência, também ganha destaque na obra de Bréal. Para ele, toda

\footnotetext{
${ }^{2}$ La science du langage est une science historique et rien d'autre qu'une science historique. (Écrits, p. 148)

${ }^{3}$ Plus on étudie la langue, plus on arrive à se pénétrer de ce fait que tout dans la langue est histoire, c'est-à-dire qu'elle est un objet d'analyse historique, et non d'analyse abstraite, qu'elle se compose de faits, et non de lois, que tout ce qui semble organique dans le langage est en réalité contingent et complètement accidentel. (Écrits, p. 149). ${ }^{4}$ Pour qu'une science soit une science historique, il faut que son objet représente des actes humains, réglés par la volonté et l'intelligence, et qui intéressent la collectivité. (GODEL, 1969, p. 38)
} 
a mudança é um empreendimento coletivo e não fruto da ação de leis estranhas aos falantes. Deixaremos essa questão em aberto, pois retornaremos a ela mais tarde, ao tratar da mudança na língua e de como esse fenômeno é abordado por ambos os teóricos. Passemos agora a outra perspectiva, vigente à época e consequente dos enquadramentos dos estudos da linguagem às Ciências Naturais: a de que as línguas seriam organismos vivos.

\subsection{As línguas não são organismos vivos}

A doutrina à qual tanto Saussure quanto Bréal opunham-se tinha como um dos principais expoentes August Schleicher, do qual se cita frequentemente a seguinte passagem: "as línguas são organismos naturais que, fora de vontade humana e seguindo leis determinadas, nascem, crescem, desenvolvem-se, envelhecem e morrem; elas manifestam, pois, também elas, essa série de fenômenos contidos habitualmente no nome vida." (ES, p. 195).

Para Bréal, o fundamento dessas afirmações encontra lugar no fato de as línguas existirem para além da vida humana - os homens morrem e as línguas permanecem - e de a duração das línguas ser medida em séculos. $\mathrm{O}$ autor contesta essas hipóteses afirmando que é difícil demarcarmos o início e o fim de uma língua, já que elas não se extinguem, mas se transformam: o português que falamos hoje é o latim falado séculos atrás. Além disso, um segundo fundamento apontado pelos naturalistas para a afirmação de que as línguas seriam organismos vivos se assentaria sobre a regularidade e a gradação dessas transformações, observáveis em várias línguas de uma mesma "família". O argumento em contrário oferecido por Bréal afirma que não são leis inerentes à linguagem que estariam na origem da marcha da mudança, mas o próprio homem, tal como o faz com outras instituições, como o direito, as crenças e até mesmo a escrita (ES, p. 196).

Bréal faz duras críticas aos comparatistas, por postularem a existência de uma protolíngua, à qual atribuiriam a pureza fonética e a transparência etimológica, uma pureza jamais encontrada em qualquer língua com a qual os indivíduos possam ter tido contato, caracterizada pelo autor como "exemplares adulterados". "É difícil compreender por que essa língua mãe suplantaria em perfeição suas filhas. [...] O erro da primeira concepção se faz sentir até no pormenor da ciência." (ES, p. 197). 
Ao contrário dessas ideias, Bréal afirma a impossibilidade de conceber a existência da linguagem fora da nossa inteligência:

Se ela [a linguagem] nos precede, e sobrevive a nós, é que ela existe na inteligência de nossos concidadãos como na nossa, é que ela existiu antes de nós em nossos pais, e de nossa parte nós a transmitimos a nossos filhos. Ela é feita do consentimento de muitas inteligências, do acordo de muitas vontades, umas presentes e atuantes, outras depois de muito tempo desfeitas e desaparecidas. (ES, p. 197)

Além disso, Bréal (1992) critica o uso de terminologias e métodos para explicar a relação entre as línguas - em especial a genealogia. A contestação do autor reside no fato de as línguas não "gerarem filhas nem darem à luz a dialetos" (ES, p. 10).

A crítica a esse postulado recebe um tom bastante semelhante no pensamento saussuriano. Ainda na primeira conferência ministrada na Universidade de Genebra, transcrita nos Escritos, Saussure menciona uma obra de M. Ovelacque, partidário da teoria de que as línguas se comportariam como organismos vivos, tendo sua existência determinada pelo seu nascimento e pela sua morte. Saussure contesta essa afirmação, argumentando que a língua não tem uma vida marcada por um nascimento e por uma morte, que as línguas não se assemelham a um organismo ou a uma vegetação cuja existência independe do homem: "a língua não é um ser organizado, ela não morre, ela não perece, ela não cresce no sentido de ter uma infância nem um amadurecimento ou uma velhice e, por fim, ela não nasce." (Écrits, p. 154) (tradução nossa). ${ }^{5}$

A ideia de que existiriam famílias linguísticas, com a existência de línguas mães e de línguas filhas, também é objetada pelo linguista genebrino. Esse pressuposto é associado àquele de que as línguas teriam uma vida finita, já que se originariam umas a partir de outras, não como uma continuação, mas como um novo ser originado de um ser precedente, com o qual guardaria algumas semelhanças. Para Saussure (2002), não existem línguas mães e línguas filhas, o que existe entre as línguas são transformações que se sucedem e não produção e reprodução de um

\footnotetext{
${ }^{5}$ La langue n'est pas un être organisé, elle ne meurt pas d'elle-même, elle ne dépérit pas, elle ne croît pas, en ce sens qu'elle n'a pas plus une enfance qu'un âge mûr ou une vieillesse, et enfin elle ne naît pas. (Écrits, p. 154).
} 
novo ser: "não existem línguas mães, não existem línguas filhas, mas uma língua que, uma vez dada, se desenvolverá indefinidamente no tempo sem qualquer termo pré-fixado à sua existência, sem que haja, até mesmo, qualquer possibilidade interior de que ela se acabe" (Écrits, p. 157) (tradução nossa). ${ }^{6}$

\subsection{A questão da mudança linguística como ação do homem em sua coletividade}

A ideia de que as línguas sofrem a ação do tempo e, principalmente, a ação do homem, além de se colocar como contrária à essência da noção de organismo, também explica por que as línguas mudam com o tempo. A essa questão, o $C L G$ dedica um capítulo aparentemente com título paradoxal: imutabilidade e mutabilidade do signo. Nesse capítulo, Saussure contesta a importância dada pelos estudos desenvolvidos à época à questão da origem da linguagem, pelo fato de considerar que a língua sempre é um produto herdado de gerações anteriores. Para ele, entretanto, é insuficiente admitir que a língua seja uma instituição herdada, é preciso ir mais longe e explicar por que e como se dá essa herança. Essa primeira consideração trata da imutabilidade do signo - e, consequentemente, da língua - justificada pela arbitrariedade do signo linguístico, pelo número de signos que compõem uma língua, pela complexidade do sistema e, por fim, pela resistência da coletividade à mudança. Vejamos cada uma delas.

A arbitrariedade do signo é apontada pelo autor como um dos fatores que desfavorecem a mutabilidade do signo, pelo fato de a relação entre significante e significado ser imotivada, o que desautoriza um possível questionamento por parte dos falantes da língua a respeito da adequação entre o conceito e a imagem acústica. $\mathrm{O}$ segundo argumento apresentado como justificativa para a incapacidade de a massa de falantes agir sobre a língua de modo a mudá-la é o fato de os signos da língua serem inumeráveis. Em terceiro lugar, é apresentada como argumento a complexidade do sistema, cujas regras são inacessíveis conscientemente para a maioria dos falantes - à exceção dos especialistas. Por fim, o último argumento exposto pelo teórico é o fato de haver resistência à mudança por

\footnotetext{
${ }^{6}$ Pas de langues mères, pas de langues filles, mais une langue une fois donne qui roulera et se déroulera indéfiniment dans le temps, sans aucun terme préfixé à son existence, sans qu'il n'y ait même de possibilité intérieure pour qu'elle finisse. (Écrits, p. 157).
} 
parte dos seus falantes, já que a língua é considerada como um produto da coletividade. Além de ser um produto da ação de forças sociais, a língua é, para autor, também um produto do tempo: a língua herdada precisa ser solidária ao passado que a engendrou e a ofereceu ao presente, o que impossibilita que qualquer falante, de modo individual, possa atuar globalmente sobre o sistema ou particularmente sobre os signos.

Por outro lado, deve-se admitir que as línguas mudam - e não morrem -, afinal, esse é um dos principais argumentos sustentados, tanto por Bréal quanto por Saussure, para negar a caracterização das línguas como organismos vivos. É para explicar a transformação que Saussure admite a mutabilidade da língua, atribuindo ao tempo, aparentemente de modo contraditório, a responsabilidade pela alteração dos signos linguísticos. É a continuidade do signo que possibilita a mudança.

Para Saussure (2006), a mudança pela qual as línguas passam não se caracterizam apenas como alterações no significante ou no significado, de modo isolado, mas, sim, de um "deslocamento da relação entre o significante e o significado" (CLG, p. 89) (grifo do autor), justificado e produzido pela arbitrariedade do signo. Se se tomasse a língua de modo independente da coletividade, e supondo que essa língua fosse falada por apenas um indivíduo, essa língua são sofreria alterações. Por outro lado, se se tomasse a língua como fruto da coletividade, mas descolada da passagem do tempo, também não seria possível observar as mudanças pelas quais ela passa. Para Saussure, apenas a conjunção das forças tempo e massa de falantes é capaz de realizar a mudança linguística.

Tais ideias, apresentadas por Bally e Sechehaye no $C L G$, são também encontradas nos Escritos. Para Saussure (2002), continuidade e mutabilidade de uma língua não são princípios contraditórios, mas complementares, já que a negação de um implica necessariamente a negação do outro. "O conjunto de considerações dessa natureza se resume, para nós, no princípio universal da absoluta continuidade da língua através do tempo. Com o primeiro princípio vem se combinar o segundo, da contínua transformação da língua através do tempo." (Écrits, p. 166) (grifos do autor, tradução nossa). ${ }^{7}$

\footnotetext{
${ }^{7}$ L'ensemble des considérations de ce genre se résument pour nous dans le principe universel de l'absolue continuité de la langue dans le temps. Avec ce premier principe venait se combiner le second, de la continuelle transformation de la langue dans le temps. (Écrits, p. 166) (grifos do autor).
} 
Assim como Saussure via o tempo como o principal fator responsável pela permanência e pela mudança das línguas, operada pelo conjunto de falantes, Bréal também teoriza que a mudança que sofrem as línguas é obra da coletividade e se dá de modo tão lento e segundo um progresso tão pouco visível que, na maioria das vezes, passa despercebida.

Sua ênfase maior, entretanto, centra-se no fato de a evolução linguística ser uma obra do conjunto de usuários. Para o autor, a ação individual sobre a língua é anulada pela maioria, ou seja, um único falante não é capaz de agir sobre a gramática ou sobre o sentido das palavras. Para Bréal, a palavra-chave para a caracterização da mudança é vontade, não a individual, mas a coletiva: "[a linguagem] é feita pelo consentimento de muitas inteligências, do acordo de muitas vontades, umas presentes e atuantes, outras depois de muito tempo desfeitas e desaparecidas" (ES, p. 197).

Pelo fato de tratar especialmente do aspecto semântico da língua, Bréal discorre demoradamente a respeito dos diversos processos pelos quais os sentidos, na língua, são modificados, incorporados, multiplicados ou desfeitos. O linguista pondera que todas as mudanças envolvendo o aspecto semântico das palavras são resultado do trabalho do "povo". Para o autor, "todos nós somos, em todos os momentos do dia, os inventores da linguagem" (ES, p. 204).

Embora não nos mesmos termos, a aproximação entre o semanticista e Saussure, com relação à mutabilidade das línguas, dáse pelo fato de Bréal admitir que não se trata de um fato necessário que a mudança aconteça tanto no aspecto formal quanto no aspecto semântico da palavra, mas que, embora não haja mudança fonética, o valor da palavra se altera distanciando-se, no mais das vezes, do seu valor etimológico. Os exemplos de mudança de sentido - e até mesmo de valor - das palavras são abundantes na obra de Bréal. Citaremos apenas um, a título de ilustração: a palavra invitare, do latim, que tem um significado próximo a convide-os a entrar. Tal vocábulo, entretanto, deriva-se de outro termo latino, invitus, que, no princípio, significava fazer violência. Bréal (1992, p. 79) explica-nos que o uso do vocábulo, por "excesso de civilidade", conduziu ao sentido de inviter (convidar). Esse exemplo - dentre muitos outros apresentados pelo autor -, elucida como o uso da língua - que é feito pelos seus falantes - é peça-chave 
para que ela mude, não apenas em seu aspecto fonético ou semântico, mas, como diria Saussure, mude a relação significante-significado.

Entretanto, a ênfase da obra de Bréal - e uma das justificativas por que tal linguista não tenha apenas se furtado à criação de uma teoria semântica, mas tenha chegado à explicação do funcionamento geral da linguagem humana - está no fato de as línguas serem uma construção coletiva. "Quanto mais a palavra se distancia de suas origens, mais está a serviço do pensamento: segundo as experiências que fazemos, ela se restringe ou se estende, se especifica ou se generaliza" (ES, p. 125).

Tal como para Saussure, para quem a língua só existe de modo completo se tomado o conjunto de seus falantes, para Bréal não é diferente, já que o autor considera que "a linguagem tem sua morada na nossa inteligência, na nossa e na de nossos concidadãos” (ES, p. 197). Não é à toa que a coletividade - e apenas ela - é capaz de atuar sobre as línguas. "Sendo a língua uma obra em colaboração, toda palavra abstrata corre o perigo de mudar de sentido, quando, passando de boca em boca, vai do inventor à multidão.” (ES, p. 100).

\subsection{Sobre o arbitrário e o valor}

Uma das primeiras considerações apontadas no capítulo sobre o valor linguístico, no $C L G$, é a relação entre dois elementos que entram em jogo no seu funcionamento: as ideias e os sons. Saussure parte desse princípio para afirmar que a língua - ou, mais precisamente, os signos é - são - o instrumento através do qual nosso pensamento se organiza. Sem o auxílio dos signos, nosso pensamento "não passa de uma massa amorfa e indistinta" (CLG, p. 130), já que estes se prestam à distinção minuciosa entre duas ideias.

Da mesma forma que Saussure, Bréal (1992, p. 165) considera que "a inteligência humana tira da linguagem [...] os mesmos serviços que ela obtém dos algarismos para o cálculo", pois é muito mais fácil operar o pensamento através dos signos do que puramente através das ideias que eles representam. Para o autor, é inquestionável o fato de a ideia ter surgido antes do signo, entretanto "essa ideia é vacilante, fugidia, difícil de transmitir; uma vez incorporada ao signo, nós ficamos mais certos de possuí-la, de manejá-la à vontade e de comunicá-la aos outros. Tal é o serviço prestado pela linguagem: ela objetiva o pensamento." 
É do fato de a língua ser um corte e uma combinação operada entre matéria fônica e pensamento que o signo é considerado arbitrário: não existe algo que justifique o laço que une forma e substância. Depecker (2012, p. 93) afirma que as relações que determinam a arbitrariedade, para Saussure, se apresentam sob três tipos: a) "a relação do signo com a coisa"; b) "a relação do signo com a ideia enquanto elemento do pensamento"; e c) "a relação interna ao signo, entre forma e ideia". A primeira dessas três possíveis relações consideradas como arbitrárias é a que encontra lugar também nos trabalhos de Bréal.

Aarsleff (1981) afirma que não há dúvidas de que, para Bréal, o signo é arbitrário. Para Bréal, as palavras da língua, tanto em seu aspecto material, quanto em seu aspecto semântico, não representam a realidade nem são dela um espelho; antes disso, "é uma transposição da realidade através de signos particulares dos quais a maior parte não corresponde a nada de real" (ES, p. 204). O semanticista afirma que não existem dúvidas de que a linguagem é incapaz de falar da realidade que designa. Essa menção à realidade se dá apenas de modo incompleto "porque não se esgotou tudo o que se pode dizer do sol quando se disse que ele é brilhante, ou do cavalo quando se disse que ele corre" e de modo inexato "porque não se pode dizer do sol que ele brilha quando se escondeu, ou do cavalo que ele corre quando está em repouso ou quando está ferido ou morto." (ES, p. 123).

Para ele, a linguagem é incapaz de apreender, em todos os pormenores, as impressões que os objetos reais despertam no que ele chama de "espírito". A língua precisa escolher entre diversas noções: "cria um nome que não tarda a se tornar um signo" (ES, p. 123). A ilusão que temos de que a língua denota objetos do mundo ou se, ao termos contato com uma palavra, temos a sensação de que ela denota algo real, é porque, segundo nos ensina o semanticista, vimos essas coisas ao ouvir esses signos (p. 205). Isso, entretanto, não justifica de forma alguma que os vocábulos tenham nascido da relação entre o mundo e a língua.

Essa afirmação é reforçada pelo fato de Bréal considerar, segundo Aarsleff (1981), que uma língua não se constitui apenas de palavras e de locuções. Para exemplificar, retoma de Bréal um exemplo no qual demonstra que, na expressão numérica 2738, cada número adquire sua função de acordo com sua posição na sequência, seja de milhar, de centena, de dezena ou de unidade. $\mathrm{O}$ autor estende para as línguas o princípio do valor adquirido em função do conjunto em se tratando de 
cifras, afirmando que "esse valor de posição existe mais ou menos em todas as línguas e, especialmente, nas línguas modernas." (BRÉAL apud AARSLEFF, 1981, p. 123) (tradução nossa). ${ }^{8}$

No Ensaio de Semântica, é possível encontrar passagens semelhantes, que entram em paralelo com o conceito de valor delineado por Saussure, especialmente quando se trata de combinações sintagmáticas. Lê-se na referida obra: "as palavras são colocadas cada vez num meio que lhe determina antecipadamente o valor" e "logo que uma palavra entra numa locução, seu sentido particular e individual é apagado para nós." (ES, p. 104; p. 189).

Arbitrariedade, portanto, é um conceito que está, segundo nossa leitura, associado àquele do valor. É pelo fato de não haver relação entre o signo e a coisa denotada que o valor de um signo é definido a partir das relações de natureza linguística, excluindo dele tudo aquilo que, de certa forma, possa remeter aos objetos denotados. É porque a relação entre o conceito e a imagem acústica é imotivada que se pode afirmar que os signos da língua valem.

No $C L G$, por outro lado, o valor de um signo é descrito segundo três aspectos: o conceitual, o material e o da totalidade do signo. O valor da parte conceitual do signo é apresentado por Saussue como derivado do concurso que o significado de um signo estabelece com os significados dos demais signos da língua, estando seu conteúdo determinado pelo que lhe é exterior. É nesse sentido que o valor é definido como uma oposição negativa, pois ele decorre da confrontação de significados. Para Saussure (2006, p. 134), as palavras que exprimem ideias semelhantes têm seu sentido delimitado de modo recíproco. É o que acontece, de acordo com o autor, com as palavras recear, temer, ter medo, cujo valor é definido pela oposição que mantêm entre si. Caso uma desaparecesse, seu significado, automaticamente, seria redistribuído entre as remanescentes. "Assim, o valor de qualquer termo que seja está determinado por aquilo que o rodeia; nem sequer da palavra que significa 'sol' se pode fixar imediatamente o valor sem levar em conta o que lhe existe em redor" (CLG, p. 135).

Tais considerações a respeito desse conceito, entretanto, não são tão inovadoras quanto se costuma afirmar. Dall Cortivo-Lebler (2014) já havia apontado que a noção de valor, tal como Saussure a concebe,

\footnotetext{
${ }^{8}$ Cette valeur de position existe plus ou moins dans toutes les langues, et tout spécialement en nos langues modernes" (BRÉAL apud AARSLEFF, 1981, p. 123).
} 
encontra fundamento no pensamento platoniano, especialmente com relação ao conceito de alteridade. E aqui chamamos a atenção para o fato de uma formulação semelhante poder ser encontrada no Ensaio de Semântica, onde Bréal afirma: "uma palavra é levada a restringir cada vez mais sua significação, pelo fato de existir uma companheira que estende o seu." (ES, p. 182).

Aarsleff (1981) destaca o fato de que os valores são sustentados pela estrutura da língua, de acordo com um jogo que coloca em equilíbrio aquilo que existe na língua e aquilo que a ela é incorporado: "toda palavra nova, introduzida na língua, causa nela uma perturbação análoga àquela de um ser novo introduzido no mundo físico ou social" (tradução nossa). ${ }^{9}$ Na mesma página, Aarsleff complementa, citando Bréal: "a linguagem, como o mundo, subsiste por forças que se mantêm em equilíbrio" (AARSLEFF, 1981, p. 124) (tradução nossa). ${ }^{10}$ Para Bréal, "nosso espírito se recusa a guardar riquezas inúteis: ele descarta pouco a pouco o supérfluo" (ES, p. 182). Essa noção de equilíbrio permanente buscado pelo sistema diz respeito não apenas à inclusão de novos termos, mas também à exclusão de termos.

\section{Para encerrar o debate}

Como mencionado na introdução deste trabalho, Guimarães (1992) chama a atenção para o fato de o conhecimento da obra de Michel Bréal, em especial do Ensaio de Semântica, ser importante na medida em que permite desautomatizar as leituras do CLG. Assim, não apenas é fundamental conhecer a obra de Bréal, mas também contextualizar em que medida seu pensamento pode ser relacionado àquele desenvolvido anos mais tarde por Saussure, em seus cursos, e conhecido através de obras como o próprio CLG, o trabalho de Godel (1969), os Escritos e das pesquisas de tantos outros estudiosos que se dedicam a desvendar os mistérios que rondam o trabalho desse grande linguista que foi Ferdinand de Saussure.

\footnotetext{
${ }^{9}$ Tout mot nouveau introduit dans la langue y cause une perturbation analogue à celle d'un être nouveau introduit dans le monde physique ou social (AARSLEFF, 1981, p. 124).

${ }^{10}$ Le langage, comme le monde, subsiste par des forces qui se tiennent en équilibre (AARSLEFF, 1981, p. 124).
} 
Nosso objetivo neste trabalho foi traçar um paralelo entre determinados conceitos e ideias desenvolvidos por Bréal e por Saussure. Vimos que Bréal, muito mais que ser o fundador da ciência das significações, delineou aspectos importantes relativamente à concepção de qual seria o objeto de estudo das ciências linguísticas, bem como a natureza deste objeto.

Aarsleff (1981) afirma que, frequentemente, se tem os alemães como as fontes que mais influenciaram o trabalho de Saussure. Entretanto, o autor considera esse argumento insustentável, já que o linguista genebrino se mostrou um grande crítico das pesquisas desenvolvidas pelos germânicos. Pelas noções apresentadas, vimos que, muito antes de qualquer semelhança com seus precursores germânicos, Saussure apresenta uma afinidade com as ideias de Bréal, especialmente no que tange a uma teorização que visa a explicar aspectos gerais da linguagem. A análise desenvolvida por ambos ultrapassou a comparação entre línguas e influenciou de modo incontornável toda a ciência linguística desenvolvida no século XX até os dias de hoje.

\section{Referências}

AARSLEFF, Hans. Bréal, la sémantique et Saussure. Histoire Épistémologie Langage. De la grammaire à la linguistique, Paris, t. 3, fasc. 2, p. 115-133, 1981. DOI: 10.3406/hel.1981.1077.

ARRIVÉ, Michel. Em busca de Ferdinand de Saussure. São Paulo: Parábola, 2010.

BOUISSAC, Paul. Saussure: um guia para perplexos. Petrópolis: Vozes, 2012.

BRÉAL, Ensaio de Semântica. São Paulo: Fontes/Educ,1992.

CÂMARA Jr., Joaquim M. Princípios de Linguística Geral. Rio de Janeiro: Livraria acadêmica, 1969.

CÂMARA JR., Joaquim M. História da Linguística. Petrópolis: Vozes, 1975.

DALL CORTIVO-LEBLER, Cristiane. A teoria da argumentação na língua e sua relação com Platão, Saussure e Benveniste: breve discussão epistemológica. Filologia e Linguística Portuguesa, São Paulo, v. 16, n. 2, p. 331-364, jul./dez. 2014. 
DEPECKER, Loïc. Compreender Saussure a partir dos manuscritos. Petrópolis: Vozes, 2012.

DUCROT, Oswald. Logique, structure, énonciation. Paris: Minuit, 1989.

GODEL, Robert. Les sources manuscrites du Cours de Linguistique Générale de Ferdinand de Saussure. Genève: Libraire Droz, 1969.

GUIMARÃES, Eduardo. A linguística é uma ciência histórica? In: BRÉAL, Michel. Ensaio de semântica. São Paulo: EDUC, 1992.

LYONS, John. Introdução à linguística teórica. São Paulo: Ed. Nacional: Ed. Universidade de São Paulo, 1979.

PICKERING, William. A influência de Darwin na teoria linguística como um prelúdio às abordagens "evolucionárias" no século 21. In: BERNARDO, Sandra; AUGUSTO, Marina R. A.; VASCONCELLOS, Zinda. Linguagem: teoria, análise e aplicações (6). Rio de Janeiro: Programa de Pós-Graduação em Letras, 2011.

SAUSSURE, Ferdinand de. Écrits de Linguistique Générale. Paris: Gallimard, 2002.

SAUSSURE, Ferdinand de. Curso de Linguística Geral. São Paulo: Cultrix, 2006.

SEIDE, Márcia Sipavicius. A semântica de Michel Bréal: recontextualização, fortuna crítica e aplicação. 2006. Tese (Doutorado em Letras) - FFLCH-USP, São Paulo, 2006.

SEIDE, Márcia S. A Semântica de Michel Bréal: uma abordagem baseada no uso. Cadernos do IL, Porto Alegre, n. 44, p. 97-116, jun. 2012. 
